\title{
Factors Affecting the Knowledge Sharing Behaviors of University Teachers: An Empirical Study in China
}

\author{
Ling Xu and Zhongwu Li
}

\begin{abstract}
Knowledge sharing among teachers denotes an important means of promoting the professional growth of individual instructors. It enhances the competitiveness of school organizations and thus constitutes a focal aspect of knowledge management in universities. This study conducts an in-depth scrutiny of the knowledge sharing behaviors of teachers, examining their sharing intentions and attitude, support received from others, self-control. With this aim, this paper obtains data from 440 college teachers in Jiangxi Province in China. It then constructs a theoretical model reflecting these factors, and the collected data were analyzed through SPSS24 and AMOS24 to obtain the results. The results of this empirical study conducted in China demonstrate that the knowledge sharing intentions of teachers positively influence their knowledge sharing behaviors. Personal knowledge sharing attitudes and support received from others also constructively affect the knowledge sharing intentions of teachers. Self-control has a negative effect on knowledge sharing intentions and exerts an indirect influence on knowledge sharing behaviors. Knowledge sharing attitudes, support received from others, and self-control are strongly and positively correlated. This investigation suggests that the knowledge sharing intentions of teachers must first be enhanced to improve their knowledge sharing behaviors. The enthusiasm of teachers to share knowledge should be stimulated, and teachers should be encouraged to freely share their understanding with others. Further, their tight regulation of self-control should be appropriately relaxed.
\end{abstract}

Index Terms-Education knowledge resource, knowledge sharing behaviors in teachers, knowledge sharing intentions, knowledge sharing attitudes, self-control.

\section{INTRODUCTION}

The value, scarcity, difficulty of imitation, and irreplaceability of knowledge [1], [2] in the current era of the knowledge economy make the sharing of knowledge an important factor in increasing an organization's competitive advantage. Knowledge helps organization members apply their theoretical understanding to innovate. The effective management of knowledge resources has become a tremendous challenge confronting organizations and their managers. Knowledge management has become a significant

Manuscript received May 11, 2021; revised July 27, 2021. This work was supported by Youth Foundation of the Ministry of Education of China (19YJC630141).

The authors are with the International College, National Institute of Development Administration, Bangkok, 10240, Thailand (corresponding author: Zhongwu Li; e-mail: dr.lingxu@nut.edu.cn, zhongwu.li@nida.ac.th). aspect of organizational management, and knowledge sharing represents the most important organizational theme and network system. Su et al. [3] state that knowledge sharing among organization members denotes the most critical facet of knowledge management. Only by promoting knowledge sharing among members can the economic and competitive value of information be realized.

As cradles of knowledge output, colleges and universities represent bases for the innovation and dissemination of knowledge and talent training. The knowledge levels of teachers determine the ability and quality of the operations of a university to a large extent, governing the institution's ability to train talent. The knowledge imbibed by teachers denotes a vital aspect of their professional qualities. Knowledge sharing helps teachers excavate and display their personal expertise and enhances their individual abilities; it also facilitates the transformation of the individual learning into group or public knowledge, further enriching and expanding the practical knowledge base of the teacher community and offering essential knowledge resources for the development of educational organizations [4], [5]. Thus, the General Office of the Chinese Government issued a document in 2016 titled Several Opinions on Implementing the Allocation Policy Oriented to Increasing the Value of Knowledge. This policy directive placed a new social focus on teachers, highlighting their roles and the allocation of their resources into society. Teachers and all their assets are protected by intellectual property laws, including their research results, academic designs, and learning materials. The Chinese government and citizenry have endeavored to stimulate innovation in researchers and educators. The entire society respects learning, talent, and creativity, and intellectual property rights are protected even as knowledge sharing is encouraged. This policy has inspired the widespread propagation of some high-quality teaching resources, such as online teaching platforms, excellent experimental platforms, and superior courses.

However, many problems have gradually emerged as the policy encouraging knowledge sharing by teachers is widely promoted. Colleges and universities generally acknowledge the importance of knowledge sharing behaviors in educational practice; however, teachers are constricted by factors such as egoism and altruism, subjective sharing desires, objective conditions, knowledge self-worth, and insufficient resource convenience. These aspects confront teachers with many obstacles to sharing their knowledge. In particular, imparting personal knowledge may reduce or even cost teachers their competitive advantage in the school organization and affect individual career development. Thus, most teachers are unwilling to share their erudition. The attitudes and intentions of teachers apropos knowledge 
sharing have become more complicated in the face of the influence of various complex factors in policy, economy, and social practice [6]. Support from others can also simultaneously affect the intentions of teachers to adopt knowledge sharing behaviors. Numerous uncertainties are also noted about whether teachers can control themselves and implement knowledge sharing behaviors. Therefore, to clarify the key reasons and factors for the teachers' knowledge sharing behavior is the prerequisite for further improving the knowledge sharing performance of teachers, and it is the top priority to establish and maintain effective knowledge management mechanism in university. There is significant practical value in examining the significations of knowledge sharing behaviors in teachers, elucidating the real factors affecting knowledge sharing behaviors in teachers, arousing the attention and importance of teachers' knowledge sharing in the education field, stimulating teachers' enthusiasm for knowledge sharing and exploring possible ways of encouraging knowledge sharing by teachers. The outcomes of such scrutiny can facilitate the inculcation of the desired knowledge sharing behaviors and add personal value to teachers, while benefiting the knowledge management levels of educational organizations with the support of theoretical and technical aspects.

\section{LITERATURE REVIEW}

Research on knowledge sharing began to be undertaken in the 1990s, spanning multiple disciplines such as sociology, psychology, economics, and pedagogy. As the literature on teacher knowledge sharing intensifies, the understanding of the connotations of such conduct also continues to deepen. Scholars believe that knowledge sharing can promote mutual learning among teachers, improve their educational efficacy, enhance pedagogic capabilities, and promote the primary objective of the professional development of teachers, which essentially entails self-learning and knowledge reconstruction during the process of knowledge transfer [7], [8]. The knowledge sharing behavior of teachers primarily involves two aspects. First, knowledge is shared through courses so teachers can themselves enhance their professional learning and academic ideas [6]. Second, knowledge may be shared by teachers through the dissemination of learning materials such as courseware, outlines, and auxiliary information [9], [10]. The first facet involves offering courses in education, which demands time from teachers and forms the core of knowledge sharing by teachers. The development of online courses has greatly reduced the costs of knowledge sharing [11] on platforms such as China MOOC, edX, netease network open course, and Chaos University, among others. Moreover, the contents of such courses can be divided into two facets [7]: professional pedagogy and academic concepts. Course materials supporting teachers, such as courseware and auxiliary information, also form a large part of knowledge sharing behaviors [12]. This study thus measures knowledge sharing from five perspectives: curriculum, professional knowledge, academic ideas, curricular materials, and auxiliary information.

The planned behavior theory mooted by Fishbein and
Fishbein and Ajzen [13] defines behavioral intention as engaging in certain conduct to satisfy specific psychological expectations. Thus, Ajzen's [14] study recommended that the measurement of consciousness should use three indicative phrases: "I intend to," "I try to," and "I plan to."

According to Ajzen [14], attitudes toward behavior depend on the desirability of results. Many other scholars have proposed similar measurement means. For example, Chen [7] suggested the question form "I feel..." for attitude measurement, along with four viable responses: good, useful, valuable, and enjoyable. Neighbors et al. [15] further classified attitude into emotion and cognition and evaluated it from both directions.

Support from others can take two principal forms: spiritual and material [16] and are extended to individuals primarily from family members [17], friends [18], colleagues [19], and social groups [20]. This study thus evaluates support from others as spiritual and material help received from family members, friends, colleagues, and social groups.

Numerous researchers have postulated a variety of self-control measurement methods in practice., Tangney et al. [21] proposed five dimensions for the measurement of self-control: thought regulation, emotional restraint, impulse checking, performance management, and habit breaking. The Cronbach's alpha value of their measurement questionnaire was computed at 0.89 . The self-control models posited by Corno [22] ameliorated the measurement dimension table of self-control through material collection and questionnaire data analysis. The scale is broadly divided into three parts. First, the sense of self-control is measured through four aspects: task efficacy, time efficacy, conscientiousness, and self-supervision. Second, the tendency of self-control is evaluated via five facets: planning, activity selectivity, persistence, summarization, and self-learning inclination. Third, the self-control strategy is assessed through four features: emotional regulation, remediation, environmental control, and help-seeking strategy.

In the existing research on the knowledge sharing of teachers, more and more experts and scholars are gradually paying attention to the importance of knowledge sharing behavior of teachers. Although the knowledge sharing behavior of teachers has attracted the attention of more and more researchers, the knowledge sharing behavior of teachers as a specialized research field has not been systematically explored, and the breadth and depth of research needs to be improved. Looking at the relevant research literature, we can see that behind the behavior of teachers' knowledge sharing, there are many influencing factors that promote or disadvantage it, and the inquiry into the influencing factors of teachers' knowledge sharing behavior is still at a relatively superficial level without more systematic and comprehensive research results. Therefore, the investigation on the factors affecting teachers' knowledge sharing behavior in university is an inevitable requirement to promote the deepening of the research field of teachers' knowledge sharing, and it is also an important way to promote the knowledge reserve and professional growth of teachers, improve the quality of education and teaching, and realize the common growth of teachers and students in university. 


\section{RESEARCH FRAMEWORK}

The theory of planned behavior posits the influence of intention or consciousness on behavior, and subsequent studies have repeatedly verified this postulation. The theory of planned behavior regards individual consciousness as a direct and primary influencing factor of behavior [23]. Before Fishbein and Ajzen [13] proposed the theory of planned behavior, they confirmed the existence of more than ten studies reporting the influence of intention on behavior and accurately calculated the value of the influencing factor as 0.63. Later, Sheppard, Hartwick, and Warshaw [24] verified this influence value as around 0.63. Van den Putte, Hoogstraten, and Meertens [25] conducted a validation test and obtained differing impact values of 0.66 and 0.68. Many scholars have subsequently analyzed the reasons and offered views and opinions on the issue.

Primarily, the theory states that intention positively affects behavior; however, intention is itself not immutable. It is inherently uncertain and is influenced by the environment, especially attitude. However, when intention influences behavior, the impact of other potential factors such as personal experience, environmental change, and individual ability cannot be excluded entirely. Therefore, the degree to which consciousness influences behavior cannot be wholly determined [26]. Therefore, this study posits the following hypothesis:

H1: The knowledge sharing intention exerts a positive influence on knowledge sharing behavior.

The positive relationship between attitudes and intentions was confirmed at the outset of the establishment of the planned behavior theory. As noted above, subsequent studies have repeatedly verified the positive influence associations. However, the studies have differed in the extent to which attitudes can affect consciousness. For example, the positive influence exerted by attitude on consciousness has been confirmed in numerous discrete disciplines, but the degree of influence was found to be affected by varied factors. Therefore, this study asserts the following hypothesis:

H2: Personal attitudes exercise a positive effect on knowledge sharing intentions.

Support received from others affects behavioral intentions, which in turn influence behavior. For example, a study of gambling found that encouragement from friends and family helped people resist the temptation to gamble. Positive assistance from friends and family can reduce intentions to gamble, thereby reducing the conduct of gambling [27]. In another instance, a study of stress perception and adolescent depression reported the significant impact of the support of peers and family members on the normal growth and development of adolescents. Positive encouragement and assistance from peers and family members negatively affects perceived stress levels and reduces the likelihood of depressive adolescent behaviors such as autism, withdrawal, and apathy [28]. Moreover, a medical study discovered that online support from others increased personal health awareness. That study was conducted with 280 overweight individuals who used an Internet forum to share their experiences of being overweight. Online supporters offered advice based on their own experiences and to help them lose weight and remain healthy. Such online assistance and encouragement greatly enhanced the health intentions of participants. Moreover, Malloch \& Zhang [29] reported that the more similar the situation is between the supporter and the supported, the more obvious the influence would be. Therefore, the present study proposes the following hypothesis:

\section{H3: Support from others positively affects the knowledge} sharing intention.

The extant literature is unclear about the relationship between self-control and shared intention; however, many studies have been conducted on the associations between self-control and shared intentions, and most of them have evidenced that self-control exerts a positive impact on intention. For example, a study on smoking first evaluated the abilities of 132 former smokers to control their reaction behaviors. It then followed up on their resumption of smoking. Nearly half of the participants recommenced their smoking habits. In addition, studies have found that people with high self-control exhibit stronger intentions of quitting smoking [30]. A study on culture and self-control development proposed that individual intentions were influenced by cultural contexts, and an interaction existed between individual intentions and the development of self-control. Personal intentions may control behavior through self-control, and self-control may also strengthen individual behaviors [31]. Van Koningsbruggen et al. [32] hypothesized in their study that individuals often forget long-term intentions because of certain influences or temptations in their environments. However, the trait of self-control enables individuals to aim at long-term goals and adhere to their intentions in their efforts to achieve long-term and persistent personal behaviors. Therefore, the fourth hypothesis for the present study is stated as follows:

H4: Self-control applies a positive effect on the knowledge sharing intention.

Substantial historical literature has demonstrated that self-control applies a significant effect on behavior. Kuhl's [33] theory of controlling behavior asserted that individual self-control exercises a direct and positive impact on learning behaviors. DeWall et al. [34] believed that self-control would consume human resources in the short term, notwithstanding the influence of emotions, intentions, or behaviors. However, the increase of self-control would be positive for both emotional and physical behaviors in the long run. From the perspective of the regulatory depletion theory, the application of self-control consumes regulatory resources; therefore, excessive self-control adversely affects behavior. To cite an example, Baumeister et al.'s [35] experiment of inverting letters found that the group with strong self-control invested more energy and resources. Although the accuracy rate of this group was higher, the duration of continuous letter recognition was significantly shorter than the length of identification displayed by the group with weak self-control. The above examples show that self-control could apply an impact on behavior. Therefore, an exploratory hypothesis is devised as follows: 
H5: Self-control applies a positive impact on knowledge sharing behaviors.

Individual attitudes and support received from others are mutually influential. A study on the use of electronic devices at a Finnish school to share information and learn Chinese divulged that teachers were more likely to encourage students to share stories and videos through e-learning platforms when students manifested positive learning attitudes. Students were also likely to harbor more positive attitudes about using knowledge sharing platforms to learn Chinese and Finnish in response to their teachers [36]. A cancer study discovered that negative support from others rendered the attitudes of cancer patients more negative. The study examined 28 cancer patients and 109 supporters. It found that their patients did not receive positive support from every helper and that some negative behaviors evinced by assisting individuals were unintentional. Excessive encouragement and attention from others were found to evoke negative attitudes in patients [37]. In another social experiment, some participants were asked to write words of support and encouragement for other participants, whose attitudes and sense of stress changed when they were surveyed after receiving encouragement. The researchers even found that participants developed more positive attitudes, such as feeling that support from others was good for their bodies and minds and helped them manage their stress levels. This case illuminates that previous researchers have contemplated the mutual influence of personal attitudes and support from others. Therefore, this study postulates the following hypotheses:

H6: A mutual influence will be observed between personal attitudes and support from others.

Support from others, especially people who are relatively important, can potentially influence individual behaviors, exerting an impact on individual self-control. Such influence ensures that people refrain from nonconforming actions to a certain extent [38]. Support from others also enhances one's sense of belonging and self-control [39]. Cohen [22] used empirical research and found that a person's willingness to control personal behavior or emotions increases when an individual exerts self-control over personal behaviors or acts in specific manners that are socially supported or considered valuable. Therefore, the following hypothesis is constructed:

H7: There is an interaction between support from others and self-control.

Bolin [40] proposed that self-control is strongly related to attitude. Giner-Sorolla's [41] study on happy subjects postulated that attitudes would affect self-control and self-control behaviors in both the long and short terms. In the first case, the self-control required to extract individuals with negative attitudes out of their predicaments was also found to be low and was accompanied by an insufficient ability to escape the difficulty. In the second instance, individuals with happy attitudes exhibited less difficulty with self-control. In the third case, negative and positive attitudes corresponded to distinct self-control responses that were accompanied by both positive and negative behaviors, language, and so on.
Babozzi et al. [42] studied the self-controlling behaviors of dieting and weight loss based on the theory of planned behavior and found that attitudes were extremely influential in explaining self-controlling behaviors in weight loss. Moreover, the norms of executive behavior, behavior perceptions, and consciousness all exercised a substantial impact on self-control behaviors. They also concluded that these three factors profoundly affected individual self-control in dieting and weight loss. Another study on alcohol consumption reported that a positive attitude toward alcohol use defeated self-controlling behaviors, and a positive attitude toward alcoholism reduced the self-control of individuals to refuse alcohol. Therefore, this study extends the following hypotheses:

H8: An interaction will exist between personal attitudes and self-control.

In sum, as Fig. 1 illustrates, the above hypotheses and their relationships constitute the framework of this study. Personal attitudes, support from others, and self-control represent the independent variables of this study. The knowledge sharing intention denotes the intermediate variable, and knowledge sharing behavior is established as the dependent variable.

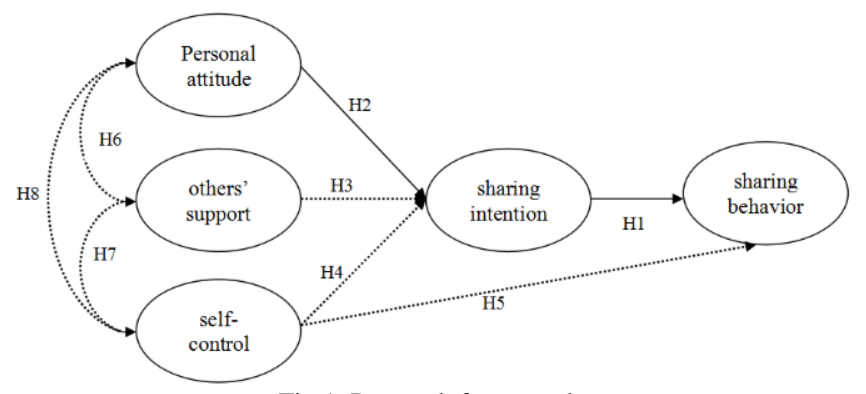

Fig 1. Research framework.

\section{Results Analysis}

In this section, the convenient sampling method was used for the data collection. There are lots of questionnaire design systems available for computer-based surveys that can give to convenience respondents while they fill in the survey. Specially, the Questionnaire Star is a professional and common data collection tool developed by the Tencent Group in China. Therefore, this paper designed a questionnaire via Questionnaire Star, and the social media platforms, such as WeChat and Tencent QQ, were applied to distribute and collect the digital questionnaires. After the data collection, to effectively analysis the date and identify the relationships among variables, the software of SPSS24 and AMOS24 were used to analyze the data and help draw study conclusions, and the structural equation modeling method was used to study and analyze multiple variables, including factor analysis and path analysis to determine the research results.

\section{A. Descriptive Analysis}

This study collected data from 440 college teachers in Jiangxi Province in China. Of the sample, $36.2 \%$ were male, and $63.8 \%$ were female. The ages of most participants could be classified into the following groups: $18-25$ (21.5\%), 
26-30 (22.7\%), 31-40 (38.7\%), and 41-50 (11.7\%). Their salaries were concentrated in three ranges: below 3000 (19.0\%), 3000-3500 (50.9\%), and 5000-8000 (23.3\%). In terms of teaching experience, $15.4 \%$ of the participating teachers had taught for less than one year, $35.6 \%$ accrued had 2-5 years of experience, $20.9 \%$ had 5-10 years, and $28.2 \%$ had experienced more than ten years of teaching. In terms of employment, $63.6 \%$ of the participating teachers were primarily employed in teaching positions, $12.9 \%$ were designated in administrative positions, and $24.5 \%$ were engaged in both. Public institutions employed $23.9 \%$ of the participating teachers, $71.2 \%$ of the sample worked at private institutions, while the rest were engaged in cooperative or other types of schools. Teachers from comprehensive colleges accounted for $55.2 \%$ of the sample, and $41.7 \%$ came from science colleges. Only a few teachers belonged to liberal arts colleges or graduate schools. The interviewed teachers were evenly distributed in representing varied disciplines, including philosophy, economics, law, management, and engineering.

\section{B. Path Analysis}

The present investigation was based on the constructed model, and the collected data were analyzed through SPSS24 and AMOS24. The original model was modified, and the study results are displayed in Fig. 2.

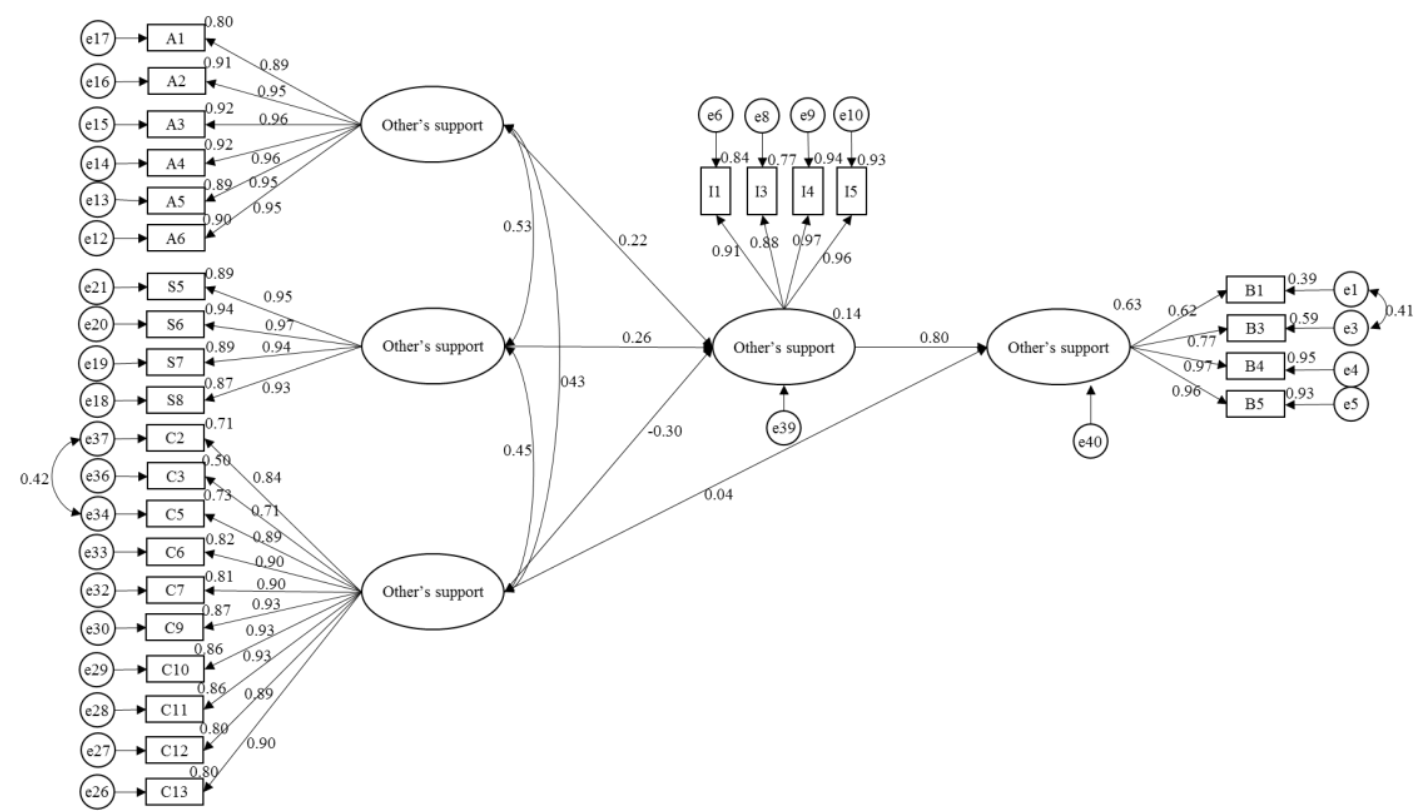

Fig. 2. Path analysis and results.

\begin{tabular}{lccl} 
& \multicolumn{3}{c}{ TABLE I: MODEL FIT DEGREE } \\
\hline \multicolumn{1}{c}{ Measure } & Original model & Modified model & \multicolumn{1}{c}{ Threshold (L. t. Hu \& Bentler, 1999) } \\
\hline Chi-square/df (CMIN/df) & 3.286 & 2.096 & $<3$ good; <5 sometimes permissible \\
p-value for the model & 0.000 & 0.000 & $>.05$ \\
CFI & 0.826 & 0.943 & $>.95$ great; $>.90$ traditional; $>.80$ sometimes permissible \\
SRMR & 0.093 & 0.090 & $<.09$ \\
RMSEA & 0.096 & 0.082 & $<.05$ good;.05-.10 moderate; $>$.10bad \\
PCLOSE & 0.000 & 0.000 & $>0.5$ \\
\hline
\end{tabular}

\begin{tabular}{|c|c|c|c|c|c|c|c|c|}
\hline \multicolumn{4}{|c|}{ Hypothesis } & \multirow{2}{*}{$\begin{array}{c}\text { Estimate } \\
0.598\end{array}$} & \multirow{2}{*}{$\frac{\text { S.E. }}{0.074}$} & \multirow{2}{*}{$\begin{array}{c}\text { C.R. } \\
8.111\end{array}$} & \multirow{2}{*}{$\begin{array}{c}\mathrm{P} \\
* * *\end{array}$} & \multirow{2}{*}{$\frac{\text { Hypothesis testing }}{\text { valid }}$} \\
\hline H1 & BEH & $<---$ & INT & & & & & \\
\hline $\mathrm{H} 2$ & INT & $<---$ & ATT & 0.218 & 0.091 & 2.405 & 0.016 & valid \\
\hline $\mathrm{H} 3$ & INT & $<---$ & $\mathrm{OTH}$ & 0.290 & 0.107 & 2.701 & 0.007 & valid \\
\hline $\mathrm{H} 4$ & INT & $<--$ & SEF & -0.376 & 0.112 & -3.359 & $* * *$ & valid \\
\hline H5 & BEH & $<---$ & SEF & 0.042 & 0.049 & 0.855 & 0.393 & Not valid \\
\hline H6 & ATT & $\langle--\rangle$ & $\mathrm{OTH}$ & 0.923 & 0.161 & 5.720 & $* * *$ & valid \\
\hline $\mathrm{H} 7$ & SEF & $\langle--\rangle$ & OTH & 0.609 & 0.125 & 4.893 & $* * *$ & valid \\
\hline $\mathrm{H} 8$ & SEF & $<-->$ & ATT & 0.684 & 0.143 & 4.781 & $* * *$ & valid \\
\hline
\end{tabular}

The residual related measurement indexes with high modified index chi-square (M.I.) value, such as A7, S1, S2, $\mathrm{S} 3, \mathrm{~S} 4, \mathrm{C} 1, \mathrm{C} 8, \mathrm{I} 2$, and B2, were deleted based on the original model. Residuals of measurement indicators such as E34 and
E37, E1, and E3 that excessively affected the model after deletion were processed. Table I demonstrates that the degree of fit of the model was greatly improved after the modification, and the standard of fit was achieved. 
The paths of the $\mathrm{p}$-values were less than 0.05 for personal attitude (ATT), support for sharing intention (INT), and support from others (OTH) on shared intentionality (INT); self-control (SEF) on shared intentionality (INT); intention (INT) of knowledge sharing on knowledge sharing behavior $(;)$; personal attitude (ATT) on support from others $(\mathrm{OTH})$; self-control (SEF) on support from others (OTH), and self-control (SEF) on personal attitude (ATT). These outcomes evidence that the path is significant. The path analysis of self-control (SEF) on shared behavior (BEH) is not significant. Table II presents the hypothesis verification.

Table II clarifies that the knowledge sharing intention of teachers exercises the strongest influence on their knowledge sharing behaviors with the positive influence value of 0.598 . In addition, individual attitudes, support from others, and self-control influence knowledge sharing behavior through the knowledge sharing intention. Personal attitudes and support from others positively influence the knowledge sharing intention and subsequently affect knowledge sharing behaviors, and their degrees of influence are computed as 0.218 and 0.290 , respectively. On the other hand, self-control negatively affects the knowledge sharing intention and then influences knowledge sharing behaviors. It does not directly affect the knowledge sharing conduct of teachers. However, personal attitudes, the support received from others, and self-control do exercise strong mutual impact, with their respective influence degrees calculated as $0.923,0.609$, and 0.684 .

\section{CONCLUSIONS}

Knowledge sharing by university teachers can integrate their professional knowledge and promote the formation of collective wisdom in school instructors. It denotes the internal driving force for the autonomous development of teachers. The exploration of factors influencing knowledge sharing behaviors in teachers can enhance the effects of knowledge sharing practices and promote the professional development of teachers. This study was based on an empirical investigation conducted in Jiangxi Province in China. It intensively examined the interrelationships between knowledge sharing behaviors evinced by teachers and their sharing intentions, sharing attitudes, support from others, and self-control. The results implied that the knowledge sharing intentions of teachers should first be improved to enhance their knowledge sharing behaviors. The knowledge sharing intentions of teachers are enhanced to some extent by motivating the positive performance of knowledge sharing. Supporting teachers in their efforts to impart their learning to others can also boost sharing intentions. However, the imposition of excessive demands on teachers to improve their self-control cannot ameliorate their knowledge sharing intentions. Conversely, the appropriate relaxation of self-control requirements can stimulate knowledge sharing intentions in teachers and can further stimulate their knowledge sharing behaviors. In sum, the knowledge sharing intentions of teachers should be stimulated by heightening their enthusiasm, supporting knowledge sharing efforts, and relaxing the mandate of self-control in order to encourage knowledge sharing behaviors in them.

\section{CONFLICT OF INTEREST}

The authors declare no conflict of interest.

\section{AUTHOR CONTRIBUTIONS}

Ling Xu and Zhongwu Li conducted the research; Ling Xu analyzed the data; Ling Xu and Zhongwu Li wrote the paper; all authors had approved the final version.

\section{REFERENCES}

[1] S. Jiafu, Y. Yu, and Y. Tao, "Measuring knowledge diffusion efficiency in R\&D networks," Knowledge Management Research \& Practice, vol. 16, pp. 208-219, 2018.

[2] X. Zhang and J. Su, "A combined fuzzy DEMATEL and TOPSIS approach for estimating participants in knowledge-intensive crowdsourcing," Computers \& Industrial Engineering, vol. 137, p. 106085, 2019.

[3] J. Su, Y. Yang, and X. Zhang, "Knowledge transfer efficiency measurement with application for open innovation networks," International Journal of Technology Management, vol. 81, pp. 118-142, 2019.

[4] M. Svensson and S. Larsson, "Intellectual property law compliance in Europe: Illegal file sharing and the role of social norms," New Media \& Society, vol. 14, pp. 1147-1163, 2012.

[5] J. Margerum-Leys and R. W. Marx, "The nature and sharing of teacher knowledge of technology in a student teacher/mentor teacher pair," Journal of Teacher Education, vol. 55, pp. 421-437, 2004.

[6] F. C. Tseng and F.-Y. Kuo, "A study of social participation and knowledge sharing in the teachers' online professional community of practice," Computers \& Education, vol. 72, pp. 37-47, 2014.

[7] C. C. Chen, "Factors affecting high school teachers'knowledge-sharing behaviors," Social Behavior \& Personality: An International Journal, vol. 39, no. 7, pp. 993-1008, 2011.

[8] L. Li, J. Xie, R. Wang, J. Su, and S. Sindakis, "The partner selection modes for knowledge-based innovation networks: A multiagent simulation," IEEE Access, vol. 7, pp. 140969-140979, 2019.

[9] L. Whent, "Factors influencing resource sharing between agriculture and science teachers participation in the agriscience program," Journal of Agricultural Education, vol. 35, pp. 11-17, 1994.

[10] Y. Xiao, C. Li, L. Song, J. Yang, and J. Su, "A multidimensional information fusion-based matching decision method for manufacturing service resource," IEEE Access, vol. 9, pp. 39839-39851, 2021.

[11] S. Kolowich, "How EdX plans to earn, and share, revenue from its free online courses," The Chronicle of Higher Education, vol. 21, pp.1-5, 2013.

[12] A. H. Wilson, "Teachers as short-term international sojourners Opening windows on the world," The Social Studies, vol. 75, pp. 153-157, 1984.

[13] M. Fishbein and I. Ajzen, "Belief, attitude, intention, and behavior: An introduction to theory and research," Philosophy and Rhetoric, vol. 10, pp. 177-188, 1977.

[14] I. Ajzen, "Perceived behavioral control, self-efficacy, locus of control, and the theory of planned behavior 1," Journal of Applied Social Psychology, vol. 32, pp. 665-683, 2002.

[15] P. A. Norberg, D. R. Horne, and D. A. Horne, "The privacy paradox: Personal information disclosure intentions versus behaviors," Journal of Consumer Affairs, vol. 41, pp. 100-126, 2007.

[16] P. A. Thoits, "Mechanisms linking social ties and support to physical and mental health," Journal of Health and Social Behavior, vol. 52, pp. $145-161,2011$

[17] D. Shenk, "Intergenerational family relationships of older women in central Minnesota," Ageing \& Society, vol. 21, pp. 591-603, 2001.

[18] M. E. Procidano and K. Heller, "Measures of perceived social support from friends and from family: Three validation studies," American Journal of Community Psychology, vol. 11, pp. 1-24, 1983.

[19] P. A. Hopkins-Thompson, "Colleagues helping colleagues: Mentoring and coaching," NASSP Bulletin, vol. 84, pp. 29-36, 2000.

[20] D. S. Şahin, Ö. Özer, and M. Z. Yanardağ, "Perceived social support, quality of life and satisfaction with life in elderly people," Educational Gerontology, vol. 45, pp. 69-77, 2019.

[21] J. P. Tangney, A. L. Boone, and R. F. Baumeister, "High self-control predicts good adjustment, less pathology, better grades, and interpersonal success," Self-regulation and self-control, pp. 173-212, 2018. 
[22] S. Cohen, "Social relationships and health," American Psychologist, vol. 59, p. 676, 2004.

[23] M. Fishbein and J. N. Cappella, "The role of theory in developing effective health communications," Journal of Communication, vol. 56, pp. S1-S17, 2006.

[24] B. H. Sheppard, J. Hartwick, and P. R. Warshaw, "The theory of reasoned action: A meta-analysis of past research with recommendations for modifications and future research," Journal of Consumer Research, vol. 15, pp. 325-343, 1988.

[25] B. Van den Putte, J. Hoogstraten, and R. Meertens, "years of the theory of reasoned action of Fishbein and Ajzen: A meta-analysis," University of Amsterdam.

[26] D. Albarracin, B. T. Johnson, M. Fishbein, and P. A. Muellerleile, "Theories of reasoned action and planned behavior as models of condom use: A meta-analysis," Psychological Bulletin, vol. 127, p. 142 2001.

[27] R. J. Martin, S. Usdan, S. Nelson, M. R. Umstattd, D. LaPlante, M Perko et al., "Using the theory of planned behavior to predict gambling behavior," Psychology of Addictive Behaviors, vol. 24, p. 89, 2010.

[28] A. Thapar, S. Collishaw, D. S. Pine, and A. K. Thapar, "Depression in adolescence," The Lancet, vol. 379, pp. 1056-1067, 2012.

[29] Y. Z. Malloch and J. Zhang, "Seeing others receive support online: Effects of self-disclosure and similarity on perceived similarity and health behavior intention," Journal of Health Communication, vol. 24, pp. 217-225, 2019.

[30] B. W. Heckman, J. W. Ditre, and T. H. Brandon, "The restorative effects of smoking upon self-control resources: A negative reinforcement pathway," Journal of Abnormal Psychology, vol. 121, p. 244, 2012.

[31] G. Trommsdorff, "Teaching and learning guide for: Culture and development of self-regulation," Social and Personality Psychology Compass, vol. 4, pp. 282-294, 2010.

[32] G. M. van Koningsbruggen, W. Stroebe, E. K. Papies, and H. Aarts, "Implementation intentions as goal primes: Boosting self-control in tempting environments," European Journal of Social Psychology, vol 41, pp. 551-557, 2011.

[33] J. Kuhl, "Volitional aspects of achievement motivation and learned helplessness: Toward a comprehensive theory of action control," Progress in Experimental Personality Research, vol. 13, Elsevier, 1984, pp. 99-171.

[34] C. N. DeWall, R. F. Baumeister, T. F. Stillman, and M. T. Gailliot, "Violence restrained: Effects of self-regulation and its depletion on aggression," Journal of Experimental Social Psychology, vol. 43, pp. 62-76, 2007.

[35] R. F. Baumeister, E. Bratslavsky, M. Muraven, and D. M. Tice, "Ego depletion: Is the active self a limited resource?" Journal of Personality and Social Psychology, vol. 74, p. 1252, 1998.

[36] A. M. Tyminski, V. S. Zambak, C. Drake, and T. J. Land, "Using representations, decomposition, and approximations of practices to support prospective elementary mathematics teachers' practice of organizing discussions," Journal of Mathematics Teacher Education, vol. 17, pp. 463-487, 2014.

[37] M. Shiozaki, K. Hirai, A. Koyama, H. Inui, R. Yoshida, and A. Tokoro, "Negative support of significant others affects psychological adjustment in breast cancer patients," Psychology \& Health, vol. 26, pp. 1540-1551, 2011.

[38] R. M. Rapee, L. Peters, L. Carpenter, and J. E. Gaston, "The Yin and Yang of support from significant others: Influence of general social support and partner support of avoidance in the context of treatment for social anxiety disorder," Behaviour Research and Therapy, vol. 69, pp. $40-47,2015$

[39] S. Gore and H. Aseltine Jr, "Protective processes in adolescence: Matching stressors with social resources," American Journal of Community Psychology, vol. 23, pp. 301-327, 1995.

[40] A. U. Bolin, "Self-control, perceived opportunity, and attitudes as predictors of academic dishonesty," The Journal of Psychology, vol. 138, pp. 101-114, 2004.

[41] R. Giner-Sorolla, "Guilty pleasures and grim necessities: Affective attitudes in dilemmas of self-control," Journal of Personality and Social Psychology, vol. 80, p. 206, 2001.

[42] R. P. Bagozzi, D. J. Moore, and L. Leone, "Self-control and the self-regulation of dieting decisions: The role of prefactual attitudes, subjective norms, and resistance to temptation," Basic and Applied Social Psychology, vol. 26, pp. 199-213, 2004.

Copyright $\odot 2022$ by the authors. This is an open access article distributed under the Creative Commons Attribution License which permits unrestricted use, distribution, and reproduction in any medium, provided the original work is properly cited (CC BY 4.0).

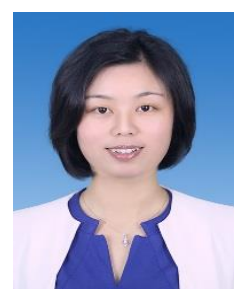

Ling Xu was born in Anqing, Anhui province, China, in 1981. She received her master's degree from Yunnan University, and now she is Ph.D student at Thailand's National Institute of Development Administration. She is currently an associate professor at Nanchang Institute of Technology. Her research interests covers knowledge management and education management.

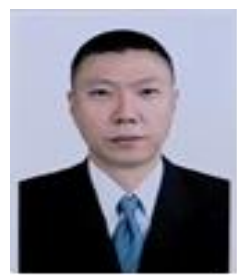

Zhongwu Li was born in Najing, China. Now, he is a Full-Time faculty member at National Institute of Development Administration of Thailand. His research interests cover public economics, managerial economics, financial management, investment and portfolio management. 